\title{
Discordar no Parlamento: estratégias de documentação
}

\author{
Maria Alina Marques \\ CEHUM / Universidade do Minho \\ mamarques@ilch.uminho.pt
}

\begin{abstract}
Resumo:
Os estudos sobre a Argumentação foram revitalizados devido ao interesse crescente pela linguagem em uso, a interacção verbal. Algumas questões teóricas tornam-se centrais. Em primeiro lugar, a transdisciplinaridade da área, levanta questões sobre a relação entre os estudos da argumentação desenvolvidos na Lógica, na Retórica e nas Ciências da Linguagem. Em segundo lugar, se falar é (inter)agir, coloca-se a questão da argumentatividade da língua face a um conceito mais restrito da argumentação como modo de organização do discurso. Finalmente, a distinção entre argumentação na língua, desenvolvimento da teoria intralinguística de Ducrot e Anscombre, e a argumentação no discurso, que congrega todas as dimensões do discurso na construção da argumentação, questiona a possível inter-relação de micro e macroanálises do discurso. O trabalho que desenvolvemos procura estabelecer ligações entre estes diferentes temas de investigação, a partir da análise de um excerto de um Debate da Interpelação ao Governo, subgénero do Discurso Político Parlamentar.
\end{abstract}

\section{Palabras chave:}

Argumentação, argumentatividade, argumentação na língua, argumentação no discurso, interacção.

\begin{abstract}
:
In the last decades, studies of argumentation have been revitalized as a result of the increasing interest in language use and dialogical interaction. Then, some theoretical issues become central. Firstly, the transdisciplinarity of the field points to an important issue: the possible relationship concerning the objects of study developed by Logic, Rhetoric and Language Sciences. Secondly, if speaking is (inter)acting, it is crucial to focus on the distinction between the concept of language argumentativity and the more restricted concept of argumentation as a form of discourse organization. Finally, different approaches of argumentation in language (Ducrot's theory) and in discourse raise the issue of microanalysis and macro-analysis of discourse argumentation. We intend to explore the relationships linking those topics of investigation in a particular text, part of a debate of Portuguese Parliamentary Discourse.
\end{abstract}

Key words:

Argumentation, argumentativity, argumentation in language, argumentation in discourse, dialogical interaction. 


\section{Argumentação e discurso}

Não argumentamos, como também não falamos, no vazio (toda a tradição retórica de Aristóteles a Perelman o afirma). A análise linguística do discurso toma-o como princípio fundamental.

Que significado poderá, pois, ter a pergunta: que é argumentar? Mais do que responder a esta questão, pretende-se considerar tal pergunta quando o objectivo é analisar o Discurso Político enquanto discurso argumentativo.

Estabelecer este objectivo e enquadramento é, de imediato, adoptar uma perspectiva de análise linguística da argumentação, mas é, também, colocar a questão da natureza da argumentação como argumentatividade generalizada, inerente à própria actividade verbal, ou como modo de organização do discurso, que justifica a classificação tipológica de discursos / textos argumentativos ${ }^{1}$.

Quanto à primeira acepção, Adam (2005) lembra que este conceito de argumentatividade poderia ser considerado ao nível das funções da linguagem tal como proposto por Bühler e Jakobson ${ }^{2}$. Cremos, no entanto, que a comparação com os conceitos de 'dialogismo' e diálogo' que, na mesma página, o autor estabelece para ilustrar a distinção entre argumentatividade e sequência argumentativa, é mais fundamental em termos da análise do discurso. Ainda que de forma indirecta, fica claro que a argumentatividade é constitutiva da língua 3 , como o dialogismo: "Comme j’ai déjà noté plus haut, il ne faut pas plus confondre l'unité compositionnelle, que je désigne sous le terme de séquence argumentative, avec l'argumentation en générale que confondre (...) le dialogisme avec le dialogue" (Adam 2005: 103).

Clarificando o uso deste termo, na adjunção que faz a duas vertentes ou perspectivas linguísticas da argumentação (argumentação em geral e a argumentação como

1 Os termos 'texto' e 'discurso' serão usados indiferenciadamente, sem considerar qualquer distinção teórica.

2 “D'un point de vue général, l'argumentation pourrait fort bien être conçue comme une quatrième ou une septième fonction du langage après les fonctions émotive-expressive, conative-impressive et référentielle de Bühler ou encore métalinguistique, phatique et poétique-autotélique de Jakobson" (Adam 2005: 103).

3 Não pretendemos advogar uma perspectiva ascritivista da língua, veja-se a Kleiber (1997), Fonseca (1992) e Charaudeau (2000) para a defesa de uma perspectiva heterogénea do sentido: "Il faut même [...] accepter qu'une même unité puisse présenter du sens mixte, relevant du statut descriptif et du statut instructionnel, Cela nous semble manifeste au niveau de la phrase, qui nous semble devoir être abordée comme ayant du sens descriptif et du sens instructionnel" (Kleiber 1997: 33); "estão consagrados na língua dois modos absolutamente heterogéneos de significar: temos o modo de significar por representação- descrição [...] e o modo de significar por mostração-indicação. É a conhecida distinção entre dizer 1 e dizer 2" (Fonseca 1992: 258); "En síntesis, se puede decir que el sentido de discurso es la resultante de dos fuerzas: una, centrífuga, que remite a las condiciones extralinguísticas de enunciación, otra, centrípeta, que organiza el sentido en una sitematicidad intralinguística" (Patrick Charaudeau 2000: 50-51). 
um modo de organização do discurso), isto é, como unidade composicional, o autor põe de lado, como é sobejamente conhecido, a categoria de texto argumentativo, por se tratar de um conceito que deriva do de sequência dominante, não de uma homogeneidade composicional que, na verdade, não ocorre. Mas não invalida, portanto, que por essa via -de sequência dominante- se chegue à classificação de discurso argumentativo: "Enfin, une dominante déterminée soi par la séquence enchâssante soit par la séquence qui permet de résumer l'ensemble du texte [...] détermine en effet de typification globale [...] qui peut faire croire à l'existence de types de textes..." (Adam 2005: 43-44).

Considerar que o Discurso Político é argumentativo, é adoptar esta segunda perspectiva de argumentação, característica de apenas algumas actividades discursivas, que ao nível da organização ilocutória do texto se configura como macroacto. Por isso tomo como exemplo as definições de argumentação propostas por Doury e Burger, que colocam a análise da argumentação no domínio das Ciências da Linguagem: "On peut alors considérer l'argumentation comme un mode de construction du discours visant à le rendre plus résistant à la contestation" (Doury 2003: 181); “Argumenter consiste à discuter et négocier un raisonnement mis en mots (Marcel Burger 2005: 64).

São definições complementares. Se a primeira põe em relevo o objectivo discursivo, sobrepor-se no confronto de um discurso e um contradiscurso, que condiciona o modo de organização textual, a segunda evidencia o processo para conseguir esse objectivo, pondo em destaque a dimensão interaccional da argumentação $0^{4}$. Mas ambos os autores partem de uma concepção de argumentação como modo particular de organização do discurso ${ }^{5}$. De notar que em ambas não se faz referência à conflitualidade frequentemente associada ao exercício prototípico da $\operatorname{argumentação}{ }^{6}$. Da mesma forma, foi 'esquecido' o conceito de persuasão. Tal tem a ver com a necessidade teórica de definir a argumentação segundo critérios linguísticos, sem recorrer a um conceito que poderemos classificar, em termos da teoria dos actos de linguagem, do domínio dos actos perlocutórios, interessando sobretudo ao campo da psicologia social (Doury 2003: 180).

4 'Discuter et négocier' têm subjacente a igualdade de papéis comunicativos de argumentador e co-argumentador.

5 Plantin (2005: 74) aponta o alcance teórico de definir a argumentação desta forma: "La définition de l'argumentation comme un mode d'organization de la parole dans des situations où elle se heurte à une contradiction ancre l'étude de l'argumentation dans celle du langage".

6 Doury (2003: 181), a propósito da argumentação no discurso quotidiano cita Plantin para lembrar que a argumentação, a "confrontation entre discours et contre-discours peut se faire aussi sur le mode conflictuel que sur le mode coopératif", não tem que estar necessariamente associada a conflitualidade. Em Plantin (2005: 66) encontramos uma explicitação de conflitualidade: "La situation de l'argumentation n'est conflictuelle que lorsque les acteurs s'identifient aux rôles argumentatifs". 
Afastam-se, pois, da relação tradicional entre argumentação e persuasão, em que aquela é definida como meio para persuadir um auditório a adoptar uma linha de acção, tal como propõe Perelman? .

A distinção agora estabelecida entre argumentação e persuasão torna especialmente evidente que a ocorrer a primeira não tem necessariamente que ocorrer a segunda, embora não sejam 'incompatíveis' ${ }^{\text {}}$. Com efeito, o discurso político parlamentar concilia as duas vertentes (Marques 2000: 172).

\section{Da argumentação na lógica à argumentação linguística}

A argumentação linguística obedece a critérios que não são estritamente lógicos, antes implica todo o processo discursivo, implica todas as dimensões do discurso, nomeadamente o quadro comunicativo e o género discursivo.

Fica pois a questão da possível relação entre a argumentação 'lógica' e a argumentação 'linguística', entre o domínio da Lógica e o domínio das Ciências da Linguagem. A diversa e específica natureza da argumentação linguística tem sido alvo de atenção alongada por parte de diferentes investigadores, nas últimas décadas. Ruth Amossy recoloca e sintetiza a questão de forma crucial, quando propõe uma distinção assente na passagem da lógica 'impessoal' à 'lógica dos sujeitos"

Ces schèmes logiques ne se laissent cependant appréhender qu'au prix d'une réduction en propositions qui élimine les complexités du discours en situation.

C'est que leur constituants ne sont pas des énoncés en langue naturelle, mais les "propositions" logiques que ces énoncés divers peuvent véhiculer [...]. Réduire les échanges verbaux à une suite logique de propositions, c'est gommer la logique des sujets dont relève le raisonnement en langue naturelle par opposition à la logique mathématique [...] et extraire le discours de l'échange où il prend sens (Amossy 2000: 115).

7 A argumentação é definida pelo autor como "les techniques discursives permettant d'accroître l'adhésion des esprits aux thèses qu'on présente à leur assentiment” (Perelman / Olbrechts-Tyteca 1970: 5).

8 Doury (2003: 180) advoga uma pluralidade de finalidades para o exercício da argumentação, que são na verdade objectivos globais da interacção: “il n'est pas possible d'attribuer une finalité unique (ni même pirncipale, à l'activité argumentative en elle-même, et que si but il y a, celui-ci est attaché à la situation de communication ou à un type d'interaction particulier, et non à l'argumentation 'en général".

9 A autora retoma, aqui, uma proposta teórica a que outros investigadores, como Plantin, têm dado destaque: "A mon sens, les études de l'argumentation ne peuvent, sans se renier, renoncer à prendre en compte le fait que le langage de l'argumentation est celui du dialogue. [...] son langage n'est pas un langage d'objets mais un langage habité par les interlocuteurs et marqué par leurs points de vue (Plantin 1990: 232). 
E por isso o exercício de tentar encontrar a ‘estrutura lógica da argumentação' sob a variedade e heterogeneidade discursivas será sempre um exercício inglório e, no mínimo, redutor:

Transformant les énoncés en une série de propositions logiques qui résument leurs contenus, elle [La reconstruction de l'enthymème] gomme tout ce qui est de l'ordre de l'interactionnel. Il ressort de ces considérations: 1. que la reconstruction du syllogisme à partir de l'enthymème est souvent trop coûteuse pour être féconde et ne constitue pas un stade obligé de l'analyse; 2 . que cette reconstruction, même aboutie, laisse souvent échapper l'essentiel de l'échange argumentatif, qui ne réside pas dans l'opération logique sous-jacente, mais dans un discours par définition dialogique où c'est la relation entre le locuteur et ses allocutaires qui donne sa force au propos (Amossy 2000: 120).

Por outro lado, se a argumentação no Discurso é diferente da argumentação na Lógica, não se segue que aquela é 'ilógica'. Num sentido amplo do termo, a argumentação não deixa de ser lógica, só que segundo a lógica da língua, a lógica dos discursos, que impõe a consideração do contexto no seu sentido mais amplo.

Vale a pena acentuar mais uma vez que a argumentação é indissociável da interacção; enquanto "logique des sujets" impõe a presença de um EU e de um TU, assume-se dialógica. Como Plantin (1993: 495) propõe, não é possível avançar na investigação da argumentação linguística se não houver integração de todas as dimensões discursivas “...il faut trouver un moyen de traiter comme un tout l'environnement discursif de l'argument et l'argument lui-même ; à la limite, la distinction doit tomber. La prise en compte de l'interaction peut permettre quelques avancées dans ce sens".

\section{A argumentação na língua e no discurso}

O lugar da argumentação nas Ciências da Linguagem é uma questão complexa. Para Plantin (1990), esta é uma questão fundadora, que passa pelo seu enquadramento como 'fait de langue' ou 'fait de discours'. Quanto à primeira vertente, a Teoria da Argumentação na Língua (TAL) desenvolvida por Ducrot / Anscombre (1983: Avant-propos) no âmbito de uma teoria do sentido é uma teoria intralinguística da argumentação: "Le sens d'un énoncé comporte, comme partie intégrante, constitutive, cette forme d'influence que l'on appelle la force argumentative. Signifier, pour un énoncé, c'est orienter”. O objecto de análise é o enunciado (ou encadeamento de dois enunciados) não o discurso. Como refere Amossy (2000: 20), a Teoria da Argumentação na Língua está limitada a uma perspectiva de microanálise, mas, e esta vertente é de facto fundamental, para a teoria da argumentação no discurso a língua não é alheia a essa dimensão argumentativa. Antes tem como 
fundamento teórico central a matriz dialógica da língua, que permite articular estas duas dimensões. Integrando conceitos elaborados no âmbito da TAL, a teoria da argumentação no discurso propõe uma abordagem da argumentação numa perspectiva de macroanálise que toma em consideração necessariamente o contributo de uma microanálise, nomeadamente o valor argumentativo das unidades linguísticas do discurso, ao serviço desse funcionamento global. É uma ligação em que a intenção global sobredetermina ao nível local as estruturas gramaticais e discursivas. Ou seja: na relação que vimos analisando, o estudo da argumentação no discurso tira partido dos desenvolvimentos teóricos da TAL. A argumentação no discurso articula as potencialidades argumentativas de categorias e funcionamentos linguísticos com funcionamentos discursivos. Orientação argumentativa dos enunciados, força do argumento, encadeamento de argumentos e topoï são conceitos da TAL fundamentais para o estudo da argumentação no discurso, porque argumentar é necessariamente usar a língua, isto é, os meios que ela nos oferece, como acentua Burger (2005: 65): "On peut détailler la dimension argumentative de notre séquence de débat en portant attention sur la valeur argumentative des unités langagières".

Reconhecendo a amplitude de análise e a heterogeneidade dos mecanismos linguísticos implicados, propomos a reflexão sobre duas questões-chave para o estudo da argumentação linguística:

a) Argumentação na língua e argumentação no discurso -convergências e potencialidades de análise.

b) Da argumentação lógica à argumentação linguística: construção da argumentação e dialogismo.

Plantin (2005: 53) afirma, a propósito, que "Il y a irréductiblement de l'énonciatif et de l'interactionnel dans l'argumentation". Daí a importância de articular os conceitos de argumentação e interacção, isto é, o dialogismo nas suas diversas componentes. Isso significa trazer o(s) Outro(s), as suas circunstâncias, o mundo, em suma, para o centro das preocupações de análise. Criar consensos / dissensos ocorre num espaço de opiniões e crenças colectivas. Trata-se de argumentar para alguém, por alguma razão (McEvoy 1993: 261): o saber partilhado e as representações sociais são a base da argumentação ${ }^{10}$.

O texto que seleccionámos para análise (retirado de um Debate da Interpelação ao Governo) permite explorar estas dimensões.

${ }^{10}$ Neste enquadramento, o conceito de escolha, convocando o conceito de estratégia discursiva, revelase fundamental. 


\section{Argumentação e discurso político}

O Discurso Político Parlamentar, e particularmente o subgénero Debate da Interpelação ao Governo, é uma prática argumentativa dialogal, marcada por uma forte ritualização (Marques 2000: 134-138), que regula, entre outros, a apresentação com antecedência do tema a debater. O conhecimento antecipado do tema ${ }^{11}$, que em termos argumentativos constitui a questão polémica ${ }^{12}$, determina que o discurso seja planeado, ainda que a organização discursiva, apesar de rígida e prédeterminada, nomeadamente no que concerne aos intervenientes, momento da intervenção e tempo de intervenção, suscite momentos de discurso semi-planeado e até mesmo não planeado (Marques 2000: 140 e 2005: 196). É, portanto, o próprio género discursivo que determina o tipo sequencial dominante: a sequência argumentativa, que permite na linha avançada por Adam (2005) classificá-lo como globalmente argumentativo.

O Debate da Interpelação ao Governo conjuga, como referido, as duas dimensões da argumentação: dar razões para fortalecer o próprio discurso, a tese a defender, numa perspectiva de, por um lado, aprofundar o dissenso (a este nível, trata-se de vincar posições que se pretendem irredutíveis) e, por outro, persuadir. A realização de ambas faz-se na criação de dois circuitos de comunicação, um relativo aos participantes no debate -deputados e membros do Governo, presentes no Parlamento-, e outro, mediado pelos meios de comunicação, entre estes participantes e o auditório identificado com o povo português (Marques 2000: 163173).

Para a nossa análise seleccionámos uma intervenção do deputado Pedro Roseta, do PSD e as réplicas ${ }^{13}$ realizadas pelos deputados Oliveira Martins, do PS, e Manuel Queiró, do CDS, (p. 649-651), ocorridas durante um debate de uma Interpelação ao Governo, o debate $\mathrm{n}^{\circ} 1 / \mathrm{VI}$, de 23 de Janeiro de 1992, publicado no Diário da República, $1^{\mathrm{a}}$ série, p. 623 a $662^{14}$. O excerto em análise está integrado no segundo

11 A pergunta ou tema é dada pela interpelação agora sujeita a debate: "O Sr. Presidente: [...] Srs. Deputados, da ordem do dia de hoje consta, como sabem, o debate da interpelação ${ }^{\circ} 1 /$ VI (PS) -Sobre política educativa" (DAR, I série, de 24 de Janeiro de 1992).

12 A polemicidade do debate é determinada desde logo pelo objectivo deste género de interacção verbal, que é de "fiscalização política pela qual os partidos obrigam o Governo a apresentar-se na Assembleia e a ser confrontado com a crítica à sua política geral ou sectorial" (Portal do Parlamento Portugués, www.parlamento.pt/glossário). Quanto à questão polémica, a definição proposta por Plantin (1996: 11) permite-nos fazer esta aproximação teórica: "L'interaction argumentative est définie comme une situation de confrontation discursive au cours de laquelle sont construites des réponses antagonistes à une question".

13 As réplicas são, em termos do Regimento da Assembleia da República, designadas como 'pedidos de esclarecimento'. 'Intervenção' é, além de uma unidade discursiva estudada pela análise conversacional, a designação que ocorre no Regimento e é usada nos debates parlamentares.

${ }^{14}$ Reproduzimos o excerto em anexo. 
período da estruturação do debate, após um período inicial em que o partido interpelante e o ministro da tutela fazem duas intervenções de fundo sobre o tema em debate ${ }^{15}$.

O local de construção do discurso é obviamente o espaço restrito do Parlamento, a sala do Hemiciclo. O circuito de divulgação é duplo: através de publicação no Diário da Assembleia da República, agora também disponível 'on line' e através dos meios de comunicação social.

A interpelação em análise, sobre política educativa, é da responsabilidade do partido Socialista, num período em que o governo é da responsabilidade do PSD.

O debate da Interpelação ao Governo, como todo o Debate Político Parlamentar, acontece no espaço-tempo de uma legislatura. É um ciclo que dá sentido aos discursos, à actividade discursiva, condicionada por um macroacto (que não é único) de persuasão, a ser actualizado pelo povo nas eleições seguintes. Além disso, cada legislatura determina a composição e função dos interactantes, independentemente de possíveis e pontuais mudanças individuais de parlamentares e membros do Governo, pois os interlocutores / polemizadores no debate são entidades colectivas, ainda que em cada debate a dimensão individual do locutor e alocutário constitua uma componente fundamental da organização enunciativa bem como da organização argumentativa do discurso.

Os interlocutores, como referido, estão pré-determinados; apenas podem participar os deputados, organizados em bancadas da oposição e bancada do Governo, e os membros do Governo. São identidades grupais que se excluem, isto é, interlocutores / adversários colectivos envolvidos numa relação discursiva polémica, bipolarizada. No Debate da Interpelação ao Governo, a argumentação é também, ou sobretudo, construção de uma posição colectiva -dos partidos e do governo, mas também dos deputados, que no Parlamento modelam o ethos colectivo mas também o ethos individual.

Se é possível estabelecer estes parâmetros gerais, é evidente que cada situação concreta constitui uma actualização específica. Isso tem a ver com a necessária articulação entre os interlocutores como indivíduos e as instituições em que o discurso como prática (linguística) social tem lugar.

\subsection{Construir a argumentação no discurso}

A intervenção está organizada segundo o esquema tradicional tripartido:

15 Sobre a estruturação do Debate da Interpelação ao Governo ver Marques (2000: 150). 
1. Sequência fática de abertura, constituída pela nomeação ritualizada dos alocutários: "Sr. Presidente, Srs. Membros do Governo, Srs. Deputados..." (linha 1).

2. Desenvolvimento, constituído por várias sequências marcadas por forte argumentatividade (1. 2-122).

3. Sequência de encerramento, "Para nós, e em conclusão..." (1. 123-128). O marcador discursivo em conclusão não é usado como conector argumentativo conclusivo, antes é um organizador do discurso, com o sentido de 'e para concluir a minha intervenção', assinalando, portanto, o encerramento discursivo.

O processo argumentativo assenta em dois desenvolvimentos cruciais: por um lado em sucessivos movimentos de objecções e refutações em que a concessividade e adversatividade ganham proeminência e por outro na convocação de vozes de autoridade que o locutor usa para credibilizar o seu dizer e, em particular, as conclusões que vai propondo.

Após a sequência de abertura, o locutor inicia uma sequência argumentativa que vai sustentar todo o processo de construção discursiva, na medida em que funciona em dois níveis, o nível local e o nível global:

1. Mais uma vez o PSD reafirma que a educação é uma prioridade inquestionável da sua acção política. Essa prioridade foi ultimamente reforçada pelos compromissos eleitorais assumidos em Outubro e pelo Programa do Governo que os consubstanciou. O Orçamento do Estado esta semana apresentado dálhe, mais uma vez, concretização. Mas a referida prioridade resulta da razão mesma de toda a actividade política: a promoção do bem comum e do respeito da dignidade de cada pessoa, a criação de condições que permitam a todos o acesso ao bem-estar e que cada pessoa em liberdade possa escolher e construir o seu próprio caminho para a felicidade (1. 4-10).

Ao nível local, o enunciado inicial é apresentado como argumento para uma conclusão a que o locutor sobrepõe, pelo uso do conector mas um segundo argumento, numa estrutura opositiva quaternária ${ }^{16} \mathrm{em}$ que as conclusões estão implícitas. $\mathrm{O}$ significado instrucional do conector mas, que é responsável por este particular micro-encadeamento, liga -segundo a TAL- dois enunciados que são dois argu-

${ }^{16}$ Cfr.: "el segundo grupo de enunciados concesivos manifestará una oposición implícita indirecta, puesto que la oposición se establecerá entre dos implicaturas derivables, cada una de ellas, de uno de los miembros del enunciado [...] sería esta una oposición totalmente dependiente del contexto y estrechamente vinculada a la situación de comunicación; una oposición propia del discurso y ausente, en definitiva, en la lengua" (Prendes 2006: 108). É uma das razões por que os conectores são fundamentais para construir estes valores. 
mentos anti-orientados para duas conclusões opostas. Numa perspectiva polifónica, complementar da TAL, o locutor assimila-se ao enunciador do segundo enunciado conferindo-lhe, assim, maior força argumentativa:

$\operatorname{Arg}_{1}$ “...o PSD reafirma que a educação é uma prioridade inquestionável da sua acção política”.

Conc. $R$ : implícita [A prioridade à educação é uma opção do foro partidário] $\mathrm{Arg}_{2}$ "Mas a referida prioridade resulta da razão mesma de toda a actividade política:...".

Conc. não R: [A prioridade à educação não é uma opção do foro partidário]

É importante em termos argumentativos e discursivos relembrar este funcionamento, porque, desde logo, há uma deslocação da 'prioridade à educação' -e do pensamento político que a sustenta- de um âmbito partidário (e contestável, portanto, em termos do quadro comunicativo do debate) para o campo dos fundamentos da própria acção política cuja essência assenta em valores que são partilhados pelos participantes no debate:

2. Mas a referida prioridade resulta da razão mesma de toda a actividade política: a promoção do bem comum e do respeito da dignidade de cada pessoa, a criação de condições que permitam a todos o acesso ao bem-estar e que cada pessoa em liberdade possa escolher e construir o seu próprio caminho para a felicidade (1. 5-8).

O aparente paradoxo - de um deputado que 'abandona' a posição partidária, que determina a sua participação no debate- é superado pelo facto de o conector mas ter aqui valor concessivo. Possibilita a deslocação do locutor, do seu estatuto de porta-voz do partido (que na realidade conserva, pois a estruturação concessiva não implica o abandono ou recusa do primeiro argumento). Ele torna-se 'voz Política' a partir da 'voz partidária'. A conjunção destes dois estatutos é fundamental para o objectivo global. Por intermédio dessa voz, o locutor opera uma conjunção de pensamentos e acções que valorizam o partido que representa.

Esta é uma estratégia ${ }^{17}$ discursiva que o locutor vai usar de forma recorrente. Efectivamente, todo o discurso assenta em agregar o particular ao geral, que aqui se quer consensual, isto é, a acção partidária à Acção Política, a opinião pessoal à opinião nacional.

\footnotetext{
17 Remetemos a Martín Menéndez (2000: 930) para o conceito de estratégia discursiva: "Las estrategias discursivas son representaciones globales de los medios que utilizamos para obtener determinado fin: son en, definitiva, modos particulares de combinar recursos para lograr una finalidad de la manera más eficaz posible".
} 
O conector mas tem aqui o significado que Ducrot analisou como próprio de 'mais PA', caracterizado pelo facto de o segundo argumento não anular o que foi afirmado no primeiro. Com efeito, 'mas', neste caso, não dá instruções para invalidar o conteúdo proposicional, o que seria realmente paradoxal, mas tão-só o valor de argumento para uma conclusão que o locutor pretende, nesta particular situação discursiva. Emma Prendes (2006: 99), reflectindo sobre a concessividade enquanto estratégia discursiva, considera que estes usos -tradicionalmente designados como adversatividade restritiva- são concessivos: "Consideraremos, en definitiva, como concesivo todo aquel enunciado que manifieste una oposición de tipo parcial, y otrora resoluble, entre alguno de sus miembros y alguna de las implicaturas que del otro miembro pudieran derivarse".

A nível global, esta primeira sequência participa da estrutura básica da argumentação, sustentada pela cadeia anafórica criada pela expressão "prioridade [à educação]".

3. Mais uma vez o PSD reafirma que a educação é uma prioridade inquestionável da sua acção política (1. 4).

4. Essa prioridade foi ultimamente reforçada pelos compromissos eleitorais assumidos em Outubro e pelo Programa do Governo que os consubstanciou (1. 2-4).

5. Mas a referida prioridade resulta da razão mesma de toda a actividade política... (1. 5-6).

6. Vou debruçar-me sobre as razões desta prioridade... (1. 9).

7. A prioridade à educação é, pois, uma exigência nacional, decorrente dos valores fundamentais aceites e consagrados na Constituição (1. 99-100).

Com efeito, a última ocorrência anafórica está integrada num enunciado que se apresenta, no uso do conector conclusivo pois como conclusão para este exercício de argumentação.

É um processo discursivo complexo pois o locutor vai desenvolver a sua argumentação tomando toda a estrutura concessiva inicial -A (logo R) mas B (logo não R)e não apenas a conclusão 'não-R' como premissa para uma nova conclusão, arrojada, que vai além dos dados, mas é sustentada pela sequência encaixada de natureza explicativa-argumentativa: "Vou debruçar-me sobre as razões desta prioridade...". A dimensão partidária vai estar presente, ainda que de forma secundarizada relativamente ao desenvolvimento discursivo e sobretudo argumentativo.

Poderemos condensar e esquematizar o processo argumentativo: ' $A$ [A (logo R) mas $\mathrm{B}(\log o$ não $\mathrm{R})$ ] por isso, $B$ [A prioridade à educação é pois uma exigência 
nacional]'. A globalidade de A permite preservar e, mais importante, defender a consonância da acção partidária com a acção política na sua essência.

Mas a conclusão assim determinada é apenas parte da conclusão global do discurso, que será introduzida a partir da especificação dos termos dessa exigência. Sobre eles encadeia a sequência argumentativa seguinte: "É fácil resolver os problemas no papel [...] que vamos atingir o essencial" (1. 114-120).

Esta sequência é fundamental para resolver a questão do lugar do locutor, como voz do partido e voz supra-partidária. Ao encerrar com esta sequência o processo de textualização da intencionalidade discursiva, o locutor dá relevo à voz partidária, que se opõe, numa imagem de responsabilidade, a uma voz não identificada, irresponsável (mas a assimilar ao alocutário dado o género discursivo em causa):

8. É fácil resolver os problemas no papel, por despacho, por decreto. Mas os reformistas sabem onde levam as perfeições escritas e as sociedades perfeitas, descritas em livros utópicos e transpostas para diplomas com força legal (1. 114-116).

Dessa oposição, o locutor deriva a conclusão global, tornando-a 'partidária', pelo encadeamento de um argumento introduzido pelo conector co-orientado aliás:

9. Na verdade a melhoria progressiva do sistema educativo só será possível com trabalho constante e generalizado, partindo do dado elementar de que não há soluções mágicas ou repentinas para todas as carências. Aliás, foi assim que o anterior Governo do PSD actuou e é com persistência na resolução de situações incompatíveis com os valores em que acreditamos que vamos atingir o essencial (1. 117-121).

De uma argumentação a partir dos valores - da Acção Política e da Constituição da República Portuguesa, necessariamente coincidentes-, o locutor deriva para uma perspectiva prática, que participa também dessa mesma 'acção política'. A prioridade à educação é uma exigência nacional que tem de ser procurada e conseguida de forma responsável e gradual. O locutor argumenta a favor, dando como exemplo dessa atitude, a acção desenvolvida pelo PSD / Governo. Por essa razão, a acção do partido / governo identifica-se com a essência da acção política. As várias sequências argumentativas / explicativas que participam da organização sequencial do texto estão ao serviço de um acto argumentativo global, que pretende tornar esta conclusão irrefutável e, desse modo, justificar as opções políticas e a prática governamental no domínio da educação.

Efectivamente, a valorização da acção partidária, relativamente à "prioridade da educação" constitui o pano de fundo de todo o discurso. A verdade é que o locutor 
começa por colocar o seu discurso relativamente ao interdiscurso, em particular a discursos políticos partidários anteriores que partilharam o mesmo tópico discursivo. A continuidade e recorrência do tema é evidenciada pelo marcador discursivo mais uma vez e pelo verbo de locução reafirmar: "Mais uma vez o PSD reafirma que a educação é uma prioridade inquestionável da sua acção política” (1. 2). É também em nome do partido, agora no uso do pronome 'nós', que o locutor encerra o discurso: "Para nós, e em conclusão, o essencial é a afirmação da nossa identidade nacional no mundo" (1. 121).

A passagem ${ }^{18}$ da estrutura argumentativa inicial, tomada como premissa, para uma conclusão é sustentada por uma longa sequência explicativa-argumentativa, que justifica o 'salto' da primeira para a segunda.

Esta justificação tem que ser compreendida relativamente aos interlocutores / adversários ${ }^{19}$. O locutor introduz explicitamente esta sequência ("Vou debruçar-me sobre as razões desta prioridade", 1. 9), que é complexa ${ }^{20}$, articulando-a em duas fase $^{21}$ que justificam a prioridade à educação em termos do papel central que tem na formação do indivíduo e da comunidade, pelo apelo aos valores (definição de educação humanista). Essas razões são apresentadas a partir de sucessivos movimentos argumentativos que permitem ao locutor fundamentar as conclusões que vai apresentar.

A estratégia discursiva usada pelo locutor assenta na convocação de vozes de autoridade, pela necessidade de legitimar uma visão da educação que ele assume como uma opinião exclusivamente individual. Cumulativamente, o locutor intercala a sua justificação de pequenos movimentos argumentativos que lhe permitem afastar possíveis contra-argumentos, e, ao mesmo tempo, clarificar as razões próprias:

10. Não ignoro que nas sociedades de hoje o desenvolvimento integral depende do nível educativo das respectivas populações e da sua capacidade em utilizar as novas tecnologias. Talvez mesmo alguns países muito desenvolvidos pudessem procurar na deterioração recente do seu nível educativo uma das causas da perda de posições relativas perante outros. Mas não posso olhar o sistema do ensino, muito menos o sistema educativo, como mero agente produtor de capital humano (1. 12-16).

${ }^{18}$ Seguimos Plantin (1990) que recupera o modelo de argumentação proposto por Toulmin (1958). É de notar que, segundo estes autores, se trata de um constituinte do esquema argumentativo básico que está muitas vezes implícito. No caso vertente, ele constitui a parte mais longa da argumentação.

19 Em relação aos interlocutores e também ao auditório, o povo português.

${ }^{20} \mathrm{Na}$ verdade, é uma sequência constituída de sequências menores encaixadas. Daí a dupla classificação de explicativa-argumentiva.

21 Por questão de espaço, apenas teremos em consideração essa primeira fase de justificação da prioridade à educação como exigência nacional. 
Essa convocação de vozes sustenta a credibilização do locutor e do seu discurso argumentativo. Pela estratégia discursiva já antes referida, de aproximação a posições gerais, inquestionáveis, o locutor identifica-se a vozes prestigiadas, a opiniões respeitadas e aceites pela comunidade. É exactamente assim que introduz a longa justificação:

11. Vou debruçar-me sobre as razões desta prioridade, que são as mesmas que levam a comunidade nacional a consagrar uma parte significativa dos seus recursos à educação (1. 9-10).

Se este processo de identificação realizado pelo locutor retira alguma pertinência informativa ao seu discurso, a verdade é que, como foi acentuado, credibiliza o seu ponto de vista. É que, por essa forma, força o adversário a, partilhando princípios / vozes incontestáveis, partilhar a contrario o ponto de vista do locutor / adversário. As vozes a citar, a forma de citação, o lugar discursivo que ocupam são fundamentais para construir a argumentação.

Neste caso que analisamos, a relação polémica com o adversário é importante. Há no Discurso Político Parlamentar uma polarização da relação e das respectivas imagens, já o afirmámos. As vozes que o locutor traz para o discurso são determinadas por essas características interaccionais. Com efeito, em citações sucessivas, ocorrem referências à educação: "o problema central da nação" (1. 10), "na feliz expressão de António José Saraiva" (1. 10), "a educação parte da cultura para a cultura" (1. 17), "como afirmou há muito Leonardo Coimbra" (1. 17), e, finalmente, "a educação [é] o modo de aprender a ser e tem em conta que a pessoa é também uma alteridade que inclui uma relação de solidariedade com os outros homens" (1. 24-26), "considera a Constituição" (1. 24). Cada definição citada sustenta a (contra-)argumentação desenvolvida pelo locutor. Por exemplo, a recusa de uma visão parcelar do sistema educativo, "como mero agente produtor de capital humano" (1. 16), a favor de "objectivos (...) mais vastos" (1. 18), é apoiada pela voz de Leonardo Coimbra; a recusa de uma concepção colectivista ou individualista da educação é suportada pela voz da Constituição:

12. Recuso a concepção colectivista que vê a educação como produtora de peças humanas para máquinas sociais concebidas e dirigidas pelo Estado. Mas recuso igualmente a concepção individualista que tende a ver na educação um meio que permite o triunfo individual dos supostamente mais capazes.

Os grandes princípios, bebidos nas raízes da nossa formação enquanto comunidade nacional e que estão consagrados na nossa Constituição, não resultam da dialéctica indivíduo / sociedade. Proclamando a dignidade da pessoa humana como fundamento da República, considera a Constituição a edu- 
cação como o modo de aprender a ser e tem em conta que a pessoa é também uma alteridade que inclui uma relação de solidariedade com os outros homens (1. 18-26).

Neste último movimento argumentativo, as escolhas lexicais marcam esta sucessiva desvalorização-valorização de diferentes conceitos de educação: aos adjectivos 'colectivista' e 'individualista' que mostram uma valorização negativa, substituemse os nomes de valorização positiva 'alteridade' e 'solidariedade'. Esta diferente valorização impede que se interprete esta 'terceira via' -que o locutor irá denominar de "educação humanista" (1. 111)- como síntese das duas anteriores.

Referir a Constituição no processo de justificação da passagem dos dados iniciais para a conclusão, é convocar uma voz de autoridade máxima, porque é um valor comum para todos estes interlocutores cuja função social é exactamente fazê-la cumprir. Nesse sentido, bastaria citar a Constituição para justificar que a prioridade à educação seja uma exigência nacional. Mas não é suficiente em termos de debate, ou melhor da relação interaccional, de polémica estabelecida, porque o debate da Interpelação ao Governo procura o dissenso.

Sendo, como está registado no Regimento da Assembleia da República, um exercício de crítica à política geral ou sectorial do Governo ele torna-se, como vimos, um debate polémico. Procura-se não apenas tornar a opinião própria aceite pelo auditório, mas simultaneamente tornar o discurso mais resistente à contra-argumentação do adversário. Porque é um debate que aprofunda o dissenso, procura, por essa forma, descredibilizar o adversário e as suas opiniões. O locutor fá-lo convocando a voz do alocutário:

13. Como um ilustre Deputado do partido interpelante, Deputado Oliveira Martins, escreveu recentemente, penso que são nefastas as perspectivas que olham a educação como uma simples preparação para a vida em lugar de a ver como expressão da própria vida (1. 27-29).

Tomar o adversário como voz de autoridade é impedir que ele, sob risco de ser acusado de incoerência, refute a argumentação desenvolvida pelo locutor.

Não é, por outro lado, como poderia parecer, uma cedência do locutor às razões do adversário. Porque, sobre a opinião deste, ele vai encadear os seus argumentos, as suas 'razões' (agora devidamente caucionadas pela voz do adversário):

14. Acrescento as minhas razões: por um lado, a educação prolonga-se ao longo de toda a vida; por outro, os jovens devem ser, desde a escola, chamados a participar na construção e aperfeiçoamento da própria sociedade (1. 2931). 
Neste discurso, o locutor argumenta no sistema de crenças do adversário. Desafiao, forçando-o a partilhar o seu ponto de vista. A acumulação de argumentos coorientados, mais do que a pertinência da conclusão visa a relação com o alocutário.

Da forma como o locutor estrutura o discurso, como estrutura a sua relação com os diferentes alocutários e destinatários se modela também a sua imagem, o seu ethos.

O estatuto dos participantes no Discurso Parlamentar é o de porta-vozes do partido ou governo e do povo português, ou seja, de vozes colectivos que são mostradas na superfície textual por formas deícticas de $1^{a}$ pessoa do plural. No entanto, o locutor individual tem também lugar e, mais ainda, projecção na interacção discursiva. O texto em análise é exemplar deste funcionamento. Se o locutor se assume como membro de um grupo, em nome do qual usa da palavra -"Para nós [...] o essencial é..." (1. 121)-, a verdade é que a dinâmica argumentativa vive de uma voz singular, que assume a fundamentação de toda argumentação: "Vou debruçar-me sobre..." (1. 9). Com efeito, o locutor explicita opiniões que assume como pessoais, até pelo uso de verbos de opinião como sei, (não) ignoro, penso, recuso. Argumenta em nome próprio. A fragilidade que poderia advir desta opinião singular é superada pela assimilação a vozes de autoridade ${ }^{22}$, que convoca e a partir das quais encadeia as razões que lhe são próprias. Há uma progressão de vozes, do Outro para o Eu:

15. Mas não posso olhar o sistema do ensino, muito menos o sistema educativo, como mero agente produtor de capital humano. Uma vez que a educação parte da cultura para a cultura, como afirmou há muito Leonardo Coimbra, os seus objectivos têm de ser mais vastos (1. 15-18).

16. Como um ilustre Deputado do partido interpelante, Deputado Oliveira Martins, escreveu recentemente [...]. Acrescento as minhas razões (1. 27-29).

17. A Constituição consagrou valores substantivos, indiscutíveis, fortemente enraizados na comunidade nacional [...]. No entanto, devo esclarecer que não tenho dos valores que referi uma visão estática... (1. 58-61).

Para o alocutário, torna-se impossível contestar o locutor sem ao mesmo tempo contestar essa voz prestigiada. Ao argumentar, claramente, a partir de crenças comuns ao alocutário para atingir objectivos partidários, o locutor legitima a sua perspectiva relativamente a ele e previne e constrange a réplica que este irá realizar. O locutor adapta-se ao Outro, fazendo com que esse Outro se reveja na representação que o locutor constrói (uma estratégia que é característica da relação com auditório, não com o adversário ${ }^{23}$ ). Ao tomar a palavra, o adversário estará limita-

22 É também sustentada pela imagem pré-discursiva do locutor, reconhecida em particular, e explicitamente, pelos adversários: "O Sr. Deputado é, decerto, a voz mais autorizada da sua bancada sobre matérias de educação" (1. 152). 
do na construção do seu (contra)discurso: de algum modo, o locutor retira-lhe pertinência como participante no debate.

Nas duas réplicas (pedidos de esclarecimento) a esta intervenção é clara esta situação.

Ao tomarem a palavra, os adversários reagem necessariamente com críticas, porque admitir o consenso absoluto seria assumir a derrota. Mas são críticas que têm como alvo dimensões do quadro comunicativo. Procuram atingir a coerência grupal, numa estratégia de divisão, marcada na estrutura condicional, a partir de um acto de elogio-crítica, na primeira réplica:

18. O Sr. Oliveira Martins (PS): -Sr. Presidente, Srs. Deputados, Sr. Deputado Pedro Roseta, é pena que o Sr. Ministro da Educação não tenha assistido ao discurso que acaba de ser feito.

Se, por um lado, o discurso do Sr. Ministro da Educação foi vago, genérico, decepcionante -aliás, quase parecia que não havia Lei de Bases do Sistema Educativo e que não estamos no decorrer da aplicação de uma reforma-, por outro o do Sr. Deputado Pedro Roseta contrasta pelo apelo aos valores, à renovação e à aposta clara nos recursos humanos (1. 131-137).

e da crítica à adequação do discurso à situação de comunicação, marcada no uso de uma estrutura concessiva, na segunda réplica:

19. O Sr. Manuel Queiró (CDS): -Sr. Deputado Pedro Roseta, a sua intervenção foi, de facto, centrada no apelo aos valores e com certeza que, apesar de ser uma exposição teórica, foi apreciada por todos (1. 150-151).

Finalmente, também a relação entre os interlocutores, que o debate político impõe, é usada pelo locutor como forma de enfraquecer o alocutário / adversário, aprofundando o dissenso e, simultaneamente, fortalecendo a sua imagem e, portanto, o seu discurso. A argumentação no discurso, sublinhamos de novo, faz intervir todas as dimensões desse mesmo discurso em que se realiza e por isso, como aponta Plantin (2005: 69), "tous les éléments entrant dans la construction d'un discours en situation peuvent être utilisés ou manipulés pour le rendre intenable".

Ora, o locutor vai precisamente usar o facto de o Debate da Interpelação ao Governo prever, relativamente aos interlocutores, uma igualdade de estatuto, uma relação simétrica, e portanto a mesma capacidade para participar no debate, ${ }^{24}$ para

\footnotetext{
${ }^{23}$ Vale a pena reafirmar que a relação entre os interlocutores é determinada pelo género e é fundamental para a argumentação. O género ‘debate' pressupõe que o locutor mostra no discurso uma imagem positiva de si e negativa do outro / adversário.
} 
desequilibrar a relação, sobrepor-se assim ao adversário e, por conseguinte, 'destruir' a relação discursiva. Com efeito, a sua estratégia é de não reconhecer o 'saber fazer' do adversário, causa de um possível ( e provável) insucesso da interacção. A agressividade que tal acusação traz é mitigada pelo facto de o locutor a fazer por meio de uma estrutura condicional, que deixa, apesar da crítica, uma imagem de tolerância, de disponibilidade para o diálogo (que o locutor, aliás, cultiva em diferentes momentos do seu discurso):

20. Se, como espero, ao longo desta interpelação e ao contrário de que até este momento fizeram os Srs. Deputados do partido interpelante ultrapassarem aquilo a que eu chamaria o imediatismo tecnocrático e não se limitarem a reclamar mais dinheiro para isto e para aquilo, estou certo que poderemos chegar a alguns pontos de convergência (1. 38-41).

\section{Conclusão}

A análise deste caso teve como objectivo primeiro ilustrar duas questões que consideramos fundamentais, a saber: a implicação da globalidade discursiva no exercício da argumentação e a importância de considerar que a argumentação é necessariamente dialógica. O Debate da Interpelação ao Governo, um dos subgéneros do Discurso Político Parlamentar, permite analisar essa dimensão argumentativa em que cada um procura fazer valer o seu discurso e, em simultâneo, mostrar que o discurso do adversário / alocutário é insustentável.

Todos os elementos que entram na construção do discurso podem ser usados para argumentar. Assim, a relação interpessoal e a imagem que o locutor constrói de si e do alocutário são fundamentais para a construção da argumentação. No texto aqui analisado, o locutor 'joga' com as constrições impostas a esse nível pelo género discursivo, de modo a pôr em causa a relação interpessoal, e por conseguinte a pertinência do lugar comunicacional do interlocutor e da própria interacção. Por um lado, vai forçar, na convocação de vozes de autoridade de origem diversa, a concordância do alocutário com as opiniões que expressa, com consequente perda de capacidade contra-argumentativa. Por outro, mas ainda na mesma linha de descredibilização do adversário, atribui-lhe a responsabilidade do (in)sucesso do debate, como se o dissenso não fosse de lei neste tipo de interacção verbal.

Na preeminência dada à argumentação como interacção, argumentar passa por prever o alocutário (e o auditório) e complementarmente dar-se a conhecer. Trata-se

24 A igualdade dos participantes é uma determinação dupla. Por um lado, pertence ao género 'debate' e, por outro, está previsto no Regimento da Assembleia da República. 
de construir verbalmente as posições divergentes através de procedimentos discursivos determinados. O locutor constrói a argumentação a partir de uma pluralidade de vozes.

Em todas as vertentes exploradas, a microanálise é indispensável à compreensão do macroacto argumentativo, porque permite recuperar, ao nível local, dimensões significativas que configuram o discurso como um todo.

\section{Referências bibliográficas}

Adam, J.-M. (2005) [1992]: Les Textes: Types et Prototypes (Paris: Armand Colin)

Adam, J.-M. (2005): "Variétés des usages de si dans l'argumentation publicitaire", em Burger, M. / Martel, G. (dirs.): Argumentation et Communication dans les Médias (Coll. Langue et pratiques discursives): 81-109 (Québec: Nota Bene).

Álvarez Prendes, E. (2006): "Hacia una tipología de los enunciados concesivos", en Actas del XXXV Simposio Internacional de la Sociedad Española de Lingüística: 88110.http://www3.unileon.es/dp/dfh/SEL/actas/Alvarez_Prendes.pdf. Consultado em 23 de Janeiro de 2007.

Amossy, R. (2000): L'argumentation dans le Discours - discours politique, littérature d'idées, fiction (Paris: Nathan).

Anscombre, J.-C. / Ducrot, O. (1983): L'Argumentation dans la Langue (Liège: Mardaga).

Burger, M. (2005): "La complexité argumentative d'une séquence de débat politique médiatique", em Burger, M. / Martel, G. (dirs.), Argumentation et Communication dans les Médias (Coll. Langue et pratiques discursives): 51-79 (Québec: Nota Bene).

Charaudeau, P. (2000): "Las Problemáticas de base de una linguística de discurso", em Bustos Tovar, J. / Charaudeau, P. / Girón Alconchel, J. L. / Iglesias Recuero, S. / López Alonso, C. (orgs.), Lengua, Discurso, Texto (I Simposio de Analisis del Discurso): 39-52 (Madrid: Visor Libros).

DAR = Diário da Assembleia da República . www.parlamento.pt. Consultado em 12 de janeiro de 2007.

Doury, M. (2003): “Argumentation et mise en voix: les discours quotidiens sur l'immigration”, em Bondi, M. I Stati, S. (dirs.), Dialogue Analysis 2000, Selected papers from the 10th IADA Anniversary Conference, Bologna 2000: 173-183 (Tübingen: Max Niemeyer Verlag). Disponível em: http://www.lcp.cnrs.fr/pdf/ dou-03a.pdf). Consultado em 23 de janeiro de 2007.

Fonseca, J. (1992): "Os elementos de coesão do texto 'Porque apoio Eanes'”, Linguística e Texto / Discurso: 315-375 (Lisboa: ICALP).

Kleiber, G. (1997): "Sens, référence et existence. Que faire de l'extra-linguistique ?", Langages 127: 9-37 (Paris: Larousse). 
Marques, M. A. (2000): Funcionamento do Discurso Político Parlamentar - organização enunciativa no Debate da Interpelação ao Governo (Braga: CEHUM / Universidade do Minho).

Marques, M. A. (2005): "Os apartes no discurso político parlamentar: vozes 'off'”, em Marques, M. A. / Koller, E. / Teixeira, J. / Sampaio, A. (orgs.), Ciências da Linguagem: 30 anos de investigação e ensino: 193-216 (Braga: ILCH / CEHUM / Universidade do Minho).

Martín Menéndez, S. (2000): "Estrategias discursivas: princípio metodológico para el análisis pragmático del discurso", em Bustos Tovar, J. / Charaudeau, P. / Girón Alconchel, J. L. / Iglesias Recuero, S. / López Alonso, C. (orgs.), Lengua, Discurso, Texto (I Simposio de Analisis del Discurso): 925-946 (Madrid: Visor Libros).

McEvoy, S. (1993): “Argumentation et justification: le cas des topoï”, em Plantin, Ch. (ed.), Lieux Communs, Topoï, Stéréotypes, Clichés: 260-270 (Paris: Kimé).

Perelman, Ch. / Olbrechts-Tyteca, L. (1970) [1958]: Traité de L'Argumentation: La nouvelle rhetorique (Bruxelles: Editions de l'Université de Bruxelles).

Plantin, Ch. (1990): Essais sur L'Argumentation - introduction à l'étude linguistique de la parole argumentative (Paris: Kimé).

Plantin, Ch. (1996): "Le trilogue argumentatif. Présentation de modèle, analyse de cas", Langue Française, 112: 9-30 (Paris: Larousse).

Plantin, Ch. (2005). L'argumentation - Histoire, théories, perspectives (Paris: PUF).

Portal do Parlamento Português, www.parlamento.pt/glossário. Consultado em 12 de

Janeiro de 2007. 


\section{Anexo:}

O Sr. Pedro Roseta (PSD): -Sr. Presidente, Srs. Membros do Governo, Srs. Deputados:

Mais uma vez o PSD reafirma que a educação é uma prioridade inquestionável da sua acção política. Essa prioridade foi ultimamente reforçada pelos compromissos eleitorais assumidos em Outubro e pelo Programa do Governo que os consubstanciou. O Orçamento do Estado esta semana apresentado dálhe, mais uma vez, concretização. Mas a referida prioridade resulta da razão mesma de toda a actividade política: a promoção do bem comum e do respeito da dignidade de cada pessoa, a criação de condições que permitam a todos o acesso ao bem-estar e que cada pessoa em liberdade possa escolher e construir o seu próprio caminho para a felicidade.

Vou debruçar-me sobre as razões desta prioridade, que são as mesmas que levam a comunidade nacional a consagrar uma parte significativa dos seus recursos à educação, que, na feliz expressão de António José Saraiva, é o "problema central da Nação".

Não ignoro que nas sociedades de hoje o desenvolvimento integral depende do nível educativo das respectivas populações e da sua capacidade em utilizar as novas tecnologias. Talvez mesmo alguns países muito desenvolvidos pudessem procurar na deterioração recente do seu nível educativo uma das causas da perda de posições relativas perante outros. Mas não posso olhar o sistema do ensino, muito menos o sistema educativo, como mero agente produtor de capital humano.

Uma vez que a educação parte da cultura para a cultura, como afirmou há muito Leonardo Coimbra, os seus objectivos têm de ser mais vastos. Recuso a concepção colectivista que vê a educação como produtora de peças humanas para máquinas sociais concebidas e dirigidas pelo Estado. Mas recuso igualmente a concepção individualista que tende a ver na educação um meio que permite o triunfo individual dos supostamente mais capazes.

Os grandes princípios, bebidos nas raízes da nossa formação enquanto comunidade nacional e que estão consagrados na nossa Constituição, não resultam da dialéctica indivíduo / sociedade. Proclamando a dignidade da pessoa humana como fundamento da República, considera a Constituição a educação como o modo de aprender a ser e tem em conta que a pessoa é também uma alteridade que inclui uma relação de solidariedade com os outros homens.

Como um ilustre Deputado do partido interpelante, Deputado Oliveira Martins, escreveu recentemente, penso que são nefastas as perspectivas que olham a educação como uma simples preparação para a vida em lugar de a ver como expressão da própria vida. Acrescento as minhas razões: por um 
40 lado, a educação prolonga-se ao longo de toda a vida; por outro, os jovens devem ser, desde a escola, chamados a participar na construção e aperfeiçoamento da própria sociedade.

A educação tem por objectivo guiar cada homem ao longo de toda a sua vida, no seu desenvolvimento integral enquanto pessoa, capaz de adquirir conhecimentos e de aderir a valores, de apreciar, agir e inovar, de adoptar o património da comunidade e de, ele próprio, o enriquecer. Deste modo, se o aspecto utilitário (chamemos-lhe assim) da educação - a capacidade para exercer uma profissão- não deve, evidentemente, ser desdenhado, o desenvolvimento global e harmonioso da personalidade em todos os seus aspectos, e tendo em conta as suas potencialidades e interesses, é que é o essencial. Sr. Presidente, Srs. Deputados: Se, como espero, ao longo desta interpelação e ao contrário de que até este momento fizeram os Srs. Deputados do partido interpelante ultrapassarem aquilo a que eu chamaria o imediatismo tecnocrático e não se limitarem a reclamar mais dinheiro para isto e para aquilo, estou certo que poderemos chegar a alguns pontos de convergência.

É que a política não se pode esgotar no enunciado de um elenco de necessidades -que todos, aliás, conhecemos: essa é uma atitude mais própria dos técnicos do que dos políticos. Só o pensamento e os valores dão coerência à acção política em geral e, evidentemente, à acção educativa. Só à sua luz é 60 possível fazer uma hierarquização das carências, dos problemas, das prioridades, atribuindo com critério os recursos, por natureza limitados, aos mais importantes ou urgentes.

Na verdade, o que distingue a política da técnica ou das ciências sociais, da sociologia ou de outras, é a capacidade de optar.

65 Ora entre os vínculos que fundamentam a comunidade está justamente a intencionalidade axiológica. Assim, a cooperação entre os homens resulta do reconhecimento dos valores comuns que tem de enformar a relação educativa.

Claro que contesto, como Francisco Sarsfield Cabral e tantos outros, a distinção que fazem os individualistas liberais entre valores processuais ou instrumentais, por um lado, e valores substantivos, por outro. Perante estes últimos teria de haver uma estrita neutralidade. A verdade é que a própria aceitação das regras de jogo em democracia implica, ela própria, "a adesão a um mínimo de valores de fundo, substantivos", como sejam: a dignidade da pessoa, o respeito da sua autonomia, a importância da paz, etc.

A Constituição consagrou valores substantivos, indiscutíveis, fortemente enraizados na comunidade nacional e que devem inspirar toda a acção educativa: além do primado da pessoa, referirei os direitos do homem, a liberdade, a justiça, a solidariedade e a igualdade de oportunidades. 
80 No entanto, devo esclarecer que não tenho dos valores que referi uma visão estática, uma vez que, em cada época, pode variar a forma por que inspiram a vida e o seu elenco pode ser enriquecido com novos valores, que venham reflectir os avanços e as esperanças de cada comunidade.

Foi, por exemplo, a extraordinária sensibilidade dos jovens às questões 85 ambientais que contribuiu decisivamente para a efectiva aceitação do direito ao ambiente como valor.

Sr. Presidente, Srs. Deputados: Esta capacidade de inovação é uma das muitas razões que me leva a afirmar que a educação de hoje ou é participada ou não é educação.

90 Se o reforço da identidade nacional terá de estar sempre presente como referência permanente, como se refere no Programa do Governo, o estímulo à capacidade criativa e inovadora de cada um é tão importante como a igualdade de oportunidades. Desta capacidade inovadora resulta o direito à diferença, consagrado no artigo $3^{\circ}$ da Lei de Bases do Sistema Educativo, que é 95 expressão do carácter único e irrepetível de cada pessoa, que, logo na escola, começa a dar o seu contributo original para a comunidade.

Sei que os restos da mentalidade jacobina e centralizadora levam alguns a ter em pouca conta as diferenças entre pessoas ou outras especificidades, por exemplo, regionais. Mas, para mim é evidente que as instituições, como as 100 escolas públicas, devem espelhar o pluralismo e a variedade, evitando sempre as tentações uniformizadoras.

No entanto, é igualmente claro que a liberdade de aprender e de ensinar não se esgota aí. A afirmação do direito dos pais, das famílias, das igrejas e outras entidades de criarem e manterem estabelecimentos de ensino próprios e 105 reconhecidos é hoje pedra de toque das democracias modernas e está consagrado nos pactos internacionais e europeus dos direitos do homem.

Também na educação o Estado não deve nem pode fazer tudo ou quase tudo mas sim reconhecer e apoiar as iniciativas criadoras dos cidadãos e da chamada sociedade civil, não esquecendo que o princípio da subsidariedade é 110 fundamental para limitar a sua acção.

É claro que a igualdade de oportunidades no acesso aos vários tipos de estabelecimentos de ensino públicos ou particulares deve ser assegurada para que a própria liberdade de aprender não seja coarctada por razões económicas ou sociais.

115 Como o Sr. Ministro da Educação já referiu, o valor fundamental que é a justiça social tem de impregnar o conjunto do sistema educativo. Por isso, o Governo se propõe alargar e reforçar a acção social escolar e corrigir um velho estado de coisas inspirado num pretenso igualitarismo que, como todas 
as intervenções do Estado com semelhante desiderato, engendrou efeitos perversos que, muitas vezes, acabam por beneficiar, por novas formas, os mais favorecidos. Não basta, pois, a intenção, também a ética de responsabilidade impõe a atenção às consequências das acções desenvolvidas.

Sr. Presidente, Srs. Deputados: Penso que, se a educação der cada vez mais relevo aos valores da comunidade e estimular as capacidades criativas, atrairá uma cada vez maior participação das comunidades locais, regionais e nacionais no processo educativo, em geral, e em cada escola, em particular, que, progressivamente, sentirão como suas. A educação deve ser "uma obra conjunta em que todos deverão intervir", como disse Leonardo Coimbra, e só a escola participada é a escola de democracia que interessa a todos os 130 cidadãos.

A prioridade à educação é, pois, uma exigência nacional, decorrente dos valores fundamentais aceites e consagrados na Constituição. Dela decorrem, e isso consta do Programa do Governo, a necessária modernização do sistema educativo nacional e a valorização, dignificação e responsabilização dos 135 docentes.

Por outro lado, ela exige o redimensionamento, a racionalização dos recursos e a avaliação posterior do seu aproveitamento e pressupõe o estímulo decidido à qualidade da educação - mas a qualidade não se decreta, não se consegue com um passe de mágica. É, pois, evidente que ela depende, sobretudo, 140 do trabalho constante, permanente e persistente e da vontade de todos e de cada um.

Pressupõe, ainda, o estímulo à criatividade, à inovação, ao diálogo, bem como à criação de condições de segurança e de bom ambiente nas escolas -e quanto a este ponto julgo que todos estaremos $100 \%$ de acordo- e exige o 145 pluralismo, nos termos acima referidos, garantindo a igualdade de oportunidades na escolha da escola pública, particular ou cooperativa.

Mas é claro que exige também, e disso estou bem consciente, para que a educação seja humanista, como preconizamos, o termo progressivo de situações que põem em causa os direitos da pessoa e que incluem, naturalmente, entre muitos outros, os casos de dependência da droga.

Sr. Presidente, Srs. Deputados: É fácil resolver os problemas no papel, por despacho, por decreto. Mas os reformistas sabem onde levam as perfeições escritas e as sociedades perfeitas, descritas em livros utópicos e transpostas para diplomas com força legal.

155 Na verdade a melhoria progressiva do sistema educativo só será possível com trabalho constante e generalizado, partindo do dado elementar de que não há soluções mágicas ou repentinas para todas as carências. Aliás, foi assim que o anterior Governo do PSD actuou e é com persistência na resolução de 
situações incompatíveis com os valores em que acreditamos que vamos atingir o essencial.

Para nós, e em conclusão, o essencial é a afirmação da nossa identidade nacional no mundo, a valorização da língua portuguesa como elemento constituinte e aglutinador dessa identidade e a criação de condições para que cada português possa trilhar livremente, desde a escola, os caminhos do seu pró-

165 prio direito à felicidade, dando a sua contribuição para a construção de uma sociedade cada vez mais livre, mais solidária e mais fraterna, que, estou certo, todos desejamos.

Aplausos do PSD.

O Sr. Presidente: -Srs. Deputados, inscreveram-se para formular pedidos de esclarecimentos os Srs. Deputados Oliveira Martins e Manuel Queiró.

Tem a palavra o Sr. Deputado Oliveira Martins.

O Sr. Oliveira Martins (PS): -Sr. Presidente, Srs. Deputados, Sr. Deputado Pedro

Roseta, é pena que o Sr. Ministro da Educação não tenha assistido ao discurso que acaba de ser feito.

Se, por um lado, o discurso do Sr. Ministro da Educação foi vago, genérico, decepcionante -aliás, quase parecia que não havia Lei de Bases do Sistema Educativo e que não estamos no decorrer da aplicação de uma reforma-, por outro o do Sr. Deputado Pedro Roseta contrasta pelo apelo aos valores, à renovação e à aposta clara nos recursos humanos.

Sr. Deputado, gostaria que me esclarecesse sobre qual a interpretação que dá a dois silêncios do discurso do Sr. Ministro da Educação, a meu ver comprometedores: um reporta-se à área de formação pessoal e social, sobre a qual nem uma palavra se disse; outro é relativo à dimensão europeia da educação, 185 sobretudo no momento em que, após Maastricht, a educação passa a ter de ser considerada como um ponto importante na política europeia.

Vozes do PS: -Muito bem!

O Sr. Presidente: -Sr. Deputado Pedro Roseta, havendo mais um orador inscrito para pedir esclarecimentos, V. Ex. ${ }^{a}$ deseja responder já ou no fim?

190 O Sr. Pedro Roseta (PSD): -No fim, Sr. Presidente.

O Sr. Presidente: -Então, tem a palavra o Sr. Deputado Manuel Queiró. 
O Sr. Manuel Queiró (CDS): -Sr. Deputado Pedro Roseta, a sua intervenção foi, de facto, centrada no apelo aos valores e com certeza que, apesar de ser uma exposição teórica, foi apreciada por todos.

195 O Sr. Deputado é, decerto, a voz mais autorizada da sua bancada sobre matérias de educação, só que estamos num debate sobre política educativa conduzida pelo Governo e, por isso, a minha pergunta tem o sentido de tentar trazêlo para esta matéria.

V. Ex ${ }^{a}$ referiu que os políticos se distinguem dos técnicos, porque fazem 200 opções, nomeadamente sobre a afectação de recursos necessariamente escassos. Bom, mas a afectação destes recursos feita por este Governo para a educação está agora consumada com a apresentação do Orçamento do Estado.

Assim, devemos supor que essa afectação de recursos não foi feita pelo Sr. Ministro das Finanças mas, sim, por opções tomadas pelo Sr. Ministro da 205 Educação.

Com efeito, o Sr. Ministro terá feito as suas opções, embora não se depreenda inteiramente da sua exposição inicial que, aliás, foi vaga quais foram.

Gostaria, pois, de saber se a sua bancada está perfeitamente ciente do sentido político dessas opções, se as conhece já há bastante tempo e qual a apreciação 210 que faz sobre o essencial dessas opções. 